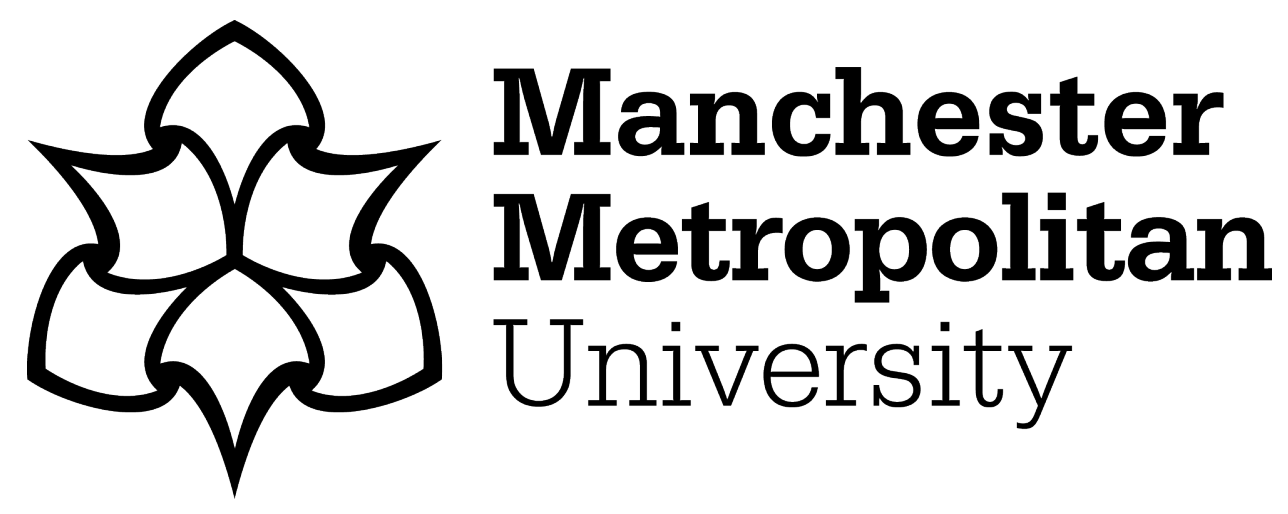

O'Keeffe, C, Houran, J, Houran, DJ, Dagnall, N ORCID logoORCID: https://orcid.org/0000-0003-0657-7604, Drinkwater, K ORCID logoORCID: https://orcid.org/0000-0002-4015-0578, Sheridan, L and Laythe, B (2019) The Dr. John Hall story: a case study in putative "Haunted People Syndrome". Mental Health, Religion and Culture, 22 (9). pp. 910-929. ISSN $1367-4676$

Downloaded from: https://e-space.mmu.ac.uk/624931/

Version: Accepted Version

Publisher: Taylor \& Francis

DOI: https://doi.org/10.1080/13674676.2019.1674795

Please cite the published version 


\section{The Dr. John Hall story: a case study in putative "Haunted People Syndrome"}

Ciaran O'Keeffe, James Houran, Damien J. Houran, Neil Dagnall, Kenneth Drinkwater, Lorraine Sheridan \& Brian Laythe

To cite this article: Ciaran O'Keeffe, James Houran, Damien J. Houran, Neil Dagnall, Kenneth Drinkwater, Lorraine Sheridan \& Brian Laythe (2019): The Dr. John Hall story: a case study in putative "Haunted People Syndrome", Mental Health, Religion \& Culture, DOI: 10.1080/13674676.2019.1674795

To link to this article: https://doi.org/10.1080/13674676.2019.1674795 


\title{
The Dr. John Hall story: a case study in putative "Haunted People Syndrome"
}

\author{
Ciaran O'Keeffe $\mathbb{D}^{a}$, James Houran $\mathbb{D}^{b}$, Damien J. Houran ${ }^{c}$, Neil Dagnall ${ }^{d}$, \\ Kenneth Drinkwater (D) ${ }^{d}$, Lorraine Sheridan (D) ${ }^{e}$ and Brian Laythe ${ }^{f}$ \\ ${ }^{\mathrm{a} D e p a r t m e n t ~ o f ~ P s y c h o l o g y, ~ B u c k i n g h a m s h i r e ~ N e w ~ U n i v e r s i t y, ~ L o n d o n, ~ U K ; ~}{ }^{\mathrm{b}}$ Instituto Politecnico de Gestao e \\ Tecnologia Escola Superior de Gestao, Portugal; ' Integrated Knowledge Systems (IKS), Dallas, TX, USA;

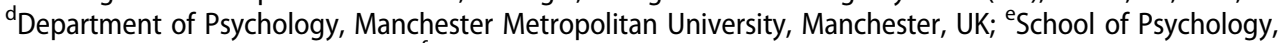 \\ Curtin University, Perth, Australia; Institute for the Study of Religious and Anomalous Experience, \\ Jeffersonville, IN, USA
}

\begin{abstract}
Research suggests a "Haunted People Syndrome (HP-S)" defined by recurrent and systematic perceptions of anomalous subjective and objective anomalies. Such signs or symptoms are traditionally attributed to "spirits and the supernatural," but these themes are hypothesised to morph to "surveillance and stalking" in reports of "group-(or gang) stalking," We tested this premise with a qualiquantitative exercise that mapped group-stalking experiences from a published first-hand account to a Rasch measure of haunttype anomalies. This comparison found significant agreement in the specific "signs or symptoms" of both phenomena. Metapatterns likewise showed clear conceptual similarities between the phenomenology of haunts and group-stalking. Findings are consistent with the idea that both anomalous episodes involve the same, or similar, attentional or perceptual processes and thereby support the viability of the HP-S construct.
\end{abstract}

\section{ARTICLE HISTORY}

Received 28 June 2019

Accepted 23 September 2019

\section{KEYWORDS}

Content analysis; delusions; encounter experiences; ghosts; group-stalking; syndrome

\section{Introduction}

Within the literature on anomalous experiences is a sub-set of intriguing reports about "haunted people" (for reviews, see e.g., Houran \& Lange, 2001; O'Keeffe \& Parsons, 2010). This terminology is deceptively simple, because the questions of "Who is haunted and also How and Why?" are bigger and thornier than might be assumed. Whatever the ultimate answers, these enigmatic occurrences span different cultures and historic eras (Maher, 2015; Roll, 1977) and seemingly represent an enduring facet of human experience. Moreover, they are clinically relevant in their capacity to foster intense sensations, perceptions, or reactions that can disrupt the daily functioning of afflicted individuals and those within their social milieus (Hastings, 1983; Montanelli \& Parra, 2002-2005; Rogo, 1982).

For example, the Doris Bither case was an alleged paranormal "haunting" that occurred in Culver City, California in the 1970s (Taff, 2014). Doris Bither, a mother of one daughter and three sons, claimed that she was repeatedly monitored, harassed, attacked, and even raped by invisible entities she believed were the ghosts of three men. In addition to Doris' 
assault claims, all four children reported seeing apparitions with the most prominent being nicknamed "Mr. Whose-it." Moreover, Doris' middle son later stated in a media interview as an adult that all his siblings also experienced some form of attack, such as pushing, pulling, biting, and scratching (Ortega, 2009). This disturbing episode inspired De Felitta's (1978) book The Entity, which was made into a 1982 film of the same name.

UCLA-based psychologists investigated the events at the time and identified numerous clinical factors likely at play, despite apparently no findings of outright psychopathology. Doris reportedly had a history of physical and substance abuse, endured multiple abusive relationships, and suffered a traumatic childhood. The family's circumstances also appeared stressful and dysfunctional from the perspective of "systems (ecosystem or biopsychosocial) theory," i.e., environment-person bidirectional influences (Mash, 1989). Indeed, the investigators observed poor relationships between Doris and her children, there was fighting among the siblings, and their house was in poor physical condition and even said to have been condemned twice, although the middle son later disputed this assertion in an interview with Ortega (2009). The son further claimed in this same interview that he and his siblings were psychic, noting that in different environments throughout their lives they had occasionally seen "shadows and spirits" - although it was only at their Culver City residence that such anomalies became negative and physical for them. The frequency and intensity of the mysterious attacks apparently decreased over time, and Doris died in the late 1990s of natural causes.

While the Doris Bither case was extreme and sensational, its phenomenology underscores why the relation between paranormal ideations and psychological wellness or symptom perception is an important and burgeoning area of study (e.g., Dein, 2012; Mathijsen, 2016; Rabeyron \& Loose, 2015; Sar, Alioğlu, \& Akyüz, 2014; Sharps et al., 2010; Simmonds-Moore, 2012). We even argue that research increasingly suggests the possibility of a Haunted People Syndrome (HP-S) ${ }^{1}$ - a moniker proposed here that was inspired by the title of an early parapsychological book by Carrington and Fodor (1951). The term "syndrome" refers to a set of signs and symptoms that occur together to characterise an abnormality or condition (British Medical Association, 2018), therefore the concept of HP-S most obviously encompasses percipients within the general population who invoke labels of ghosts or other supernatural agencies to explain a specific set of anomalous events that often are perceived recurrently.

Investigators often designate these anomalies as either Subjective ( $S$, internal or psychological) or Objective ( $O$, external or physical). Subjective includes sensed presences, hearing voices, unusual somatic or emotional manifestations, and perceptions of human forms. Objective comprises apparent object movements, malfunctioning of electrical or mechanical equipment, and inexplicable percussive sounds like raps or knockings (for reviews of these S/O anomalies see e.g., Dagnall, Drinkwater, Denovan, \& Parker, 2015; Drinkwater, Dagnall, Denovan, \& Parker, 2019; Houran, 2000). We should also emphasize that paranormal attributions by witnesses to these "signs or symptoms" are not surprising given the prevalence of "ghosts" as both beliefs and memetic cultural narratives (Bader, 2017; Booker, 2009; Goldstein, Grider, \& Thomas, 2007; Hill et al., 2018, 2019).

However, context effects can produce different interpretations or attributions for nearly identical $S / O$ anomalies. To be sure, reports of apparitions and poltergeists resemble, and might equate to, accounts of other "entity encounter experiences," such as angels, demons, extraterrestrials, Men in Black (MIBs), shamanic spirit guides, and folklore-type 
beings (Evans, 1987, 2001; Houran, 2000; Hufford, 1982, 2001). Such studies imply the existence of an underlying experience or phenomenon that changes its appearance in accordance with the situation or sociocultural context in which it manifests. For instance, Musgrave and Houran (2000) outlined similar structures and contents between Medievalera experiences, known as the flight to the Witches' Sabbat, and modern-era accounts of UFO abductions.

Likewise, Lange and Houran (2001a) have further contended that the phenomenology of ghostly episodes strongly parallels cases of mass psychogenic illness whereby individuals suffer from mysterious contaminants, pathogens, or even man-made stimuli (Balaratnasingama \& Janca, 2006; Chen, Yen, Lin, \& Yang, 2003; Colligan, Pennebaker, \& Murphy, 1982; Wessely, 1987, 2000). ${ }^{2}$ To illustrate, both outbreaks comprise ambiguous stimulants that trigger a sudden onset and cessation of often dramatic symptoms (psychological or physical), many times in young females, and during times of psychosocial stress (Boss, 1997; Lange \& Houran, 2001a). Other times, similar experiences induced by suggestion have been misattributed to mainstream technologies (e.g., O'Mahony, 1978; Radford \& Bartholomew, 2001). Finally, both haunts and psychogenic illness involve psychological contagion, or the instigation of successive (episodic) experiences in individuals or groups due to expectancy effects (Houran \& Lange, 1996a, 1996b; Lange \& Houran, 2001a, 2001b; Laythe, Laythe, \& Woodward, 2017; O’Keeffe \& Parsons, 2010).

Haunt and poltergeist accounts might therefore represent merely one portrayal of an adaptable "core" phenomenon that we denote as HP-S. We further presume this core experience is produced via "the right people in the right settings" (Laythe, Houran, \& Ventola, 2018, p. 210). Specifically, Rasch $(1960,1980)$ scaling studies suggest there is a probabilistic hierarchy of 32 "base" anomalous events (Houran et al., 2019a, 2019b). These manifest typically in psychosocial or physical environments linked to physiological arousal (Houran, Kumar, Thalbourne, \& Lavertue, 2002; Jawer, 2006). Moreover, individuals higher in transliminality (thin mental boundaries) tend to report these experiences to a greater extent (Laythe et al., 2018), which implies a heightened susceptibility to higharousal or "dis-ease" states (Evans, Lange, Houran, \& Lynn, 2018; Ventola et al., 2019).

\section{Group-Stalking - A Haunt by another name?}

We suspect that the concept of HP-S might help to explain contemporary accounts of reputed "group (or gang)-stalking" — or what Hall (2014) described as "organized stalking" (p. 47). Seminal research by Sheridan and James (2015) suggested that this phenomenon differs from stalking cases involving lone-culprits and is arguably delusional in nature. Here, victims state that they are being targeted by coordinated groups of people. Paullet, Rota, and Swan (2009) defined it more formally as stalking that "involves the use of multiple individuals to stalk, harass or threaten the victim" (p. 640). Additionally, the stalking being the apparent work of a social system acting in concert, it is usually not possible for alleged victims to identify the lead person responsible for directing or implementing the activities. Likewise, the victim is generally unable to provide any evidence as to who is behind the stalking, although the person may attribute it to a specific source like an ex-partner or covert government agency.

Based on his interviews with many alleged "targeted individuals (or T.I.s)," Hall (2014, p. 69) proposed six phases to the group-stalking phenomenon: selection, surveillance, 
stalking, defamation, attack, and monitoring. This is reminiscent of certain patterns noted in parapsychological studies. First, T.I.s mirror the concept of "focus persons" in hauntpoltergeist outbreaks, that is, living individuals around whom the anomalies tend to centre (see e.g., Roll, 1977; Laythe et al., 2018). Next, experiences in haunt-poltergeist accounts often appear episodic. Like some illnesses, Nisbet (1979) proposed that poltergeist-like episodes have an incubation period before anomalies manifest. The $S / O$ events then apparently progress in stages over time (for a discussion, see e.g., Houran et al., 2019a).

Table 1 shows that Sheridan and James' (2015) signs or symptoms of group-stalking can be categorised as $\mathrm{S} / \mathrm{O}$ events. Furthermore, Table 2 affirms that the themes in these events resemble, at least superficially, those reported in accounts of ghostly episodes (cf. Houran et al., 2019a; Houran \& Lange, 2001). However, T.I.s, interpret these core symptoms as clearly non-paranormal. More precisely, the traditional religio-cultural constructs of "spirits, spooks, and the supernatural" ostensibly morph to the modern techno-concepts of "satellites, surveillance, and stalking." For example, consider a detailed description from an online poster who addressed the question, "How do you know if you're being gang-stalked?"13 -

In my case ... it all stopped just as suddenly and unexplainable as it had all started. The first symptoms I noticed ... Things would be moved, there was evidence of breaking and entering. This progressed to my place of employment... Then I was assaulted in my sleep. My food and/or drink was most likely poisoned while I was gone from my house.

There were ... individuals following me, and an over saturation of law enforcement near my home and job... There were strange phone calls at all hours and inappropriate times. There were "street theatre" incidents and coincidences that were just not mathematically possible.

Table 1. Symptoms of group-stalking (Sheridan \& James, 2015: Table 1, pp. 9-10) categorized by subjective (psychological) vs. objective (physical) experiences.

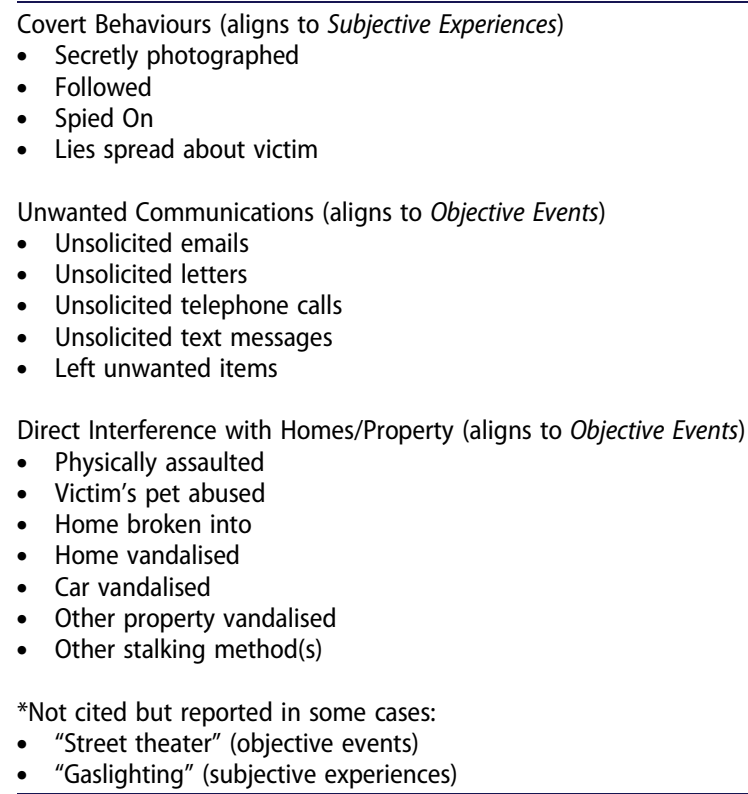


Table 2. Common group-stalking symptoms and Hall's (2009) specific experiences mapped to the hierarchical Survey of Strange Events (SSE).

Group (or gang)-Stalking "Signs/ Rasch Hierarchy of Haunt-type Experiences (descending order - $\quad$ Symptoms" (Sheridan \& James, common to rare events: Houran et al., 2019b) 2015)

\# of Reported

I had a sense of déjà vu, like something was vaguely familiar to me about my thoughts, feelings, or surroundings.

I had the mysterious feeling of being watched, or in the presence of an invisible being or force.

- Secretly photographed

- Followed

- Spied On

I heard mysterious "mechanical" or non-descript noises, such as tapping, knocking, rattling, banging, crashing, footsteps or the sound of opening/closing doors or drawers.

I felt a mysterious area of cold.

I felt a breeze or a rush of wind or air, like something invisible was moving near me.

I saw with my naked eye a non-descript visual image, like fog, shadow or unusual light.

I heard mysterious sounds that could be recognized or identified, such - Lies spread about victim as ghostly voices or music (with or without singing).

Electrical or mechanical appliances or equipment functioned improperly or not at all, including flickering lights, power surges or batteries "going dead" in electronic devices (e.g., camera, phone, etc.).

I had a negative feeling for no obvious reason, like anger, sadness, panic, or danger.

I was mysteriously touched in a non-threatening manner, like a tap, touch or light pressure on my body.

I saw with my naked eye an "obvious" ghost or apparition - a misty or translucent image with a human form.

I saw with my naked eye an "un-obvious" ghost or apparition - a human form that looked like a living person.

- Secretly photographed

- Followed

- Spied On

I felt odd sensations in my body, such as dizziness, tingling, electrical shock, or nausea (sick in my stomach).

I experienced objects disappear or reappear around me.
- Unsolicited telephone calls

Unsolicited text messages

- Unsolicited emails
Ch. 22 (p. 94)

Hall's (2009) Group-Stalking Experiences

Ch. 4 (p. 20), Ch. 8 (p. 35), Ch. 16 (p. 68)

Ch. 8 (p. 35, 37), Ch. 11 (p. 48), Ch. 14 (p. 59), Ch. 18 (p. 76), Ch. 20 (p. 87), Ch. 22 (p. 94)
Events in Hall (2009)

Ch. 3 (p. 14, 16, 17), Ch. 10 (p.42, 43, 44), Ch.11 (p.46), Ch. 13 (p. 55), Ch. 15 (p.64), Ch. 16 (p. 69), Ch. 18 (p. 76), Ch. 20 (p. 85), Ch. 22 (p. 96), Ch. 23 (p. 101), Ch. 24 (p. 104, 105)

Ch. 5 (p. 23, 24), Ch. 8 (p.35), Ch. 21 (p. 89, 90), Ch. 23 (p. 100, 102), Ch. 24 (p. 105)

Ch. 3 (p. 36), Ch. 9 (p. 40), Ch. 10 (p. 42), Ch. 11 (p.47, 48, 49), Ch. 12 (p. 53), Ch. 14 (p. 60), Ch. 17 (p. 73), Ch. 18 (p. 76, 77, 78, 79), Ch.20 (p. 86, 87), Ch. 21 (p. 92), Ch. 22 (p. 94, 96)

Ch. 5 (p. 24, 25) Ch. 10 (p. 45) Ch. 12 (p. 52, 53), Ch. 13 (p. 58), Ch. 16 (p. 69), Ch. 17 (p. 73), CH. 18 (p. 79), Ch. 20 (p. 80) Ch. 20 (p. 87), Ch. 23 (p. 100, 102) 
Table 2. Continued.

\begin{tabular}{ll}
\hline Rasch Hierarchy of Haunt-type Experiences (descending order - & Group (or gang)-Stalking "Signs/ \\
Symptoms" (Sheridan \& James,
\end{tabular}

common to rare events: Houran et al., 2019b)

2015)
- Unsolicited letters

Pictures from my camera or mobile device captured unusual images, shapes, distortions or effects.

I smelled a mysterious odor that was pleasant.

I communicated with the dead or other outside force.

I saw objects moving on their own across a surface or falling.

I had a positive feeling for no obvious reason, like happiness, love, joy, or peace.

I heard on an audio recorder mysterious "mechanical" or non-descript noises, such as tapping, knocking, rattling, banging, crashing, footsteps or the sound of opening/closing doors or drawers.

I heard on an audio recorder mysterious sounds that could be

recognized or identified, such as ghostly voices or music (with or without singing).

I smelled a mysterious odor that was unpleasant.

I was mysteriously touched in a threatening manner, such as a cut,

bite, scratch, shove, burn or strong pressure on my body.

- Physically assaulted

- Victim's pet abused

I saw objects breaking (or discovered them broken), like shattered or - Home broken into cracked glass, mirrors or housewares.

- Home vandalised

- Car vandalised
\# of Reported

Events in Hall

(2009)

Hall's (2009) Group-Stalking Experiences

I saw objects flying or floating in midair.

I felt a mysterious area of heat.

I felt guided, controlled or possessed by an outside force.

Plumbing equipment or systems (faucets, disposal, toilet) functioned improperly or not at all.

I saw beings of divine or evil origin, such as angels or demons.

I had a mysterious taste in my mouth.

I saw folklore-type beings that were not human, such as elves, fairies,

or other types of "little people."

Fires have started mysteriously.

Ch. 21 (p. 90)

Ch. 4 (p. 19), Ch. 10 (p. 43,45$)$

Ch. 13 (p. 56, 57)

Ch. 11 (p. 49), Ch. 13 (p. 56, 57), Ch. 14 (p. 59, 60), Ch. 17 (p. 74) CH. 20 (p. 85, 87), Ch.22 (p. 95)

Ch. 17 (p.73), Ch. 23 (p.101)

Ch. 12 (p. 54), Ch. 15 (p. 63), Ch 16. (p. 69), Ch. 18 (p. 78, 79), Ch 24 (p. 104, 105), Ch. 25 (p. 112)

Ch. 2 (p. 13), Ch. 6 (p. 28), Ch. 8 (p. 35), Ch. 9 (p. 40), Ch. 10 (p. 42 44, 45), Ch. 12 (p. 52), Ch. 14 (p. 59), Ch. 17 (p. 73), Ch. 19 (p.81),

Ch. 20 (p. 87), Ch. 23 (p. 100, 102), Ch. 24 (p. 104)

Ch. 5 (p. 24), Ch. 16 (p. 69), Ch. 23 (p. 101), Ch. 24 (p. 104) Ch. 9 (p. 41), Ch. 10 (p. 42,45), Ch. 11 (p. 49, 50), Ch. 12 (p. 52), Ch. 
There were encounters with people in public that I would see dressed differently or under a different guise at various places...

There was the constant knowledge that I was being watched. There was a constant echo or static only found in wiretapping on all my phone calls. There were random people that would show up at my job and just hand me a piece of paper with nothing on it, and quickly leave. I saw the same sets of people on websites or random online pages.

My computer was obviously and carelessly hacked... There was a constant parade of clear human shadows on my bedroom walls at night ... the more you try to explain this phenomena (sic) to friends and family, the more they withdraw from believing that anything at all is happening to you. Then I woke up one day after approximately 5 years of constant terror and being victimized, and poof! It stopped (emphasis in original).

\section{The Dr. John hall story}

There is an active and worldwide sub-culture of people devoted to public awareness of reputed group-stalking, similar to the prevalent groups of paranormal enthusiasts and "ghost-hunters" (Hill, 2017). Google the phrase "victims of group-stalking" and over nine-million entries emerge. Many lay-organizations and individual activists within this vast community identify John Hall, a Texas-based anesthesiologist, as among its most credible and authoritative figures (McPhate, 2016).

Notwithstanding legitimate controversies about some covert surveillance programmes as famously discussed by Edward Snowden (e.g., Burrough, Ellison, \& Andrews, 2014), or the exploitations of personal-data mining by technology companies (e.g., Zuboff, 2019), satellite-stalking and related claims might sound like science fiction to many people. Yet, Hall $(2009,2011)$ ardently believes that it is the future of criminal assault due to his first-hand experiences and ongoing research, as documented in two books to date. An off-handed comment to Hall by an academic colleague who claimed to have an important connection with an ex-FBI agent (ironically known as "The Ghost") was the apparent catalyst to mysterious events and intrusions that next unfolded in Hall's life. This onslaught started with what Hall deemed to be regular "druggings," as well as break-ins to his house and those of people close to him.

The chronology of Hall's (2009) personal experiences lacks ample detail for robust timeseries analyses on potential psychological "contagion" effects (cf. Lange \& Houran, 2001a, 2001b), but his published narrative is amenable to a content analysis. In this respect, we explore two hypotheses: (i) the discrete experiences or events in Hall's stalking narrative will reliably and substantively correspond to the base experiences that define witness narratives in ghostly episodes, and (ii) the overarching phenomenology of Hall's set of experiences will most align to the meta-patterns exhibited by spontaneous ("sincere and unprimed") accounts of ghostly episodes, as opposed to control accounts that derive from fantasy, deliberate deceit, or types of priming conditions.

\section{Method}

\section{Spontaneous case data}

Data derived from Hall's (2009) 127-page, commercial book, which the publisher described on its back cover as "Dr. Hall's narration ... based on true-life events." It is uncertain to what 
extent this text represents Hall's own words or those of a copyeditor. Also, we made no attempt to corroborate any of his claims. Instead, our analysis focussed only on identifying the presence and pattern of themes within his broad narrative. Thus, this source data is similar to previous content analyses of paranormal accounts (e.g., Harte, 2000; Houran, 2000).

\section{Measure}

The Survey of Strange Events (SSE; Houran et al., 2019b) is a 32-item, "true/false" Rasch (1960/1980) scaled measure of the overall intensity of a "ghostly account or narrative" via a weighted checklist of base events (psychological and physical) inherent to these episodes. We refer readers to our previous papers for details on the development of this instrument (Houran et al., 2019a, 2019b). Rasch scores range from 22.3 (= raw score of 0) to 90.9 (= raw score of 32$)(M=50, S D=10)$, with a Rasch person reliability of .87 . Higher scores correspond to a greater number and intensity of anomalies that define a percipient's experience. Furthermore, supporting the SSE's content and predictive validities, Houran et al. (2019b) found that the phenomenology of "spontaneous" accounts (i.e., sincere and unprimed) differed significantly from "control" narratives derived from primed conditions, fantasy scenarios, or deliberate fabrication.

\section{Content Category Dictionary (CCD)}

CCD is used to retest existing categories, concepts, or models in new contexts (Catanzaro, 1988). We designed and implemented a two-tier, deductive protocol using a categorisation matrix based on the SSE measure described above (cf. Column 1: Table 2). An experimentally-blind rater reviewed Hall's (2009) self-reported group-stalking experiences and coded their alignment with the SSE categories. To decrease bias and increase reliability, we presented Hall's (2009) experiences anonymously (i.e., without context). The rater examined the transcripts and recorded the items from the categorisation matrix based on whether they were present or not. To optimise the accuracy of the final codings, another independent rater with expertise in anomalistic psychology subsequently cross-checked the classifications against the source material.

\section{Results}

\section{Hypothesis 1}

Table 2 shows that the raters who studied Hall's (2009) account as a "T.I." reliably identified 18 out of the 32 base anomalies characteristic of haunt narratives, i.e., a $~ 56 \%$ correspondence in themes. This tally converts to an above-average Rasch scaled score of 58.5 (SE = 2.6) on the SSE, which agrees with the idea that group-stalking experiences significantly overlap with specific anomalies in accounts of ghostly encounters.

\section{Hypothesis 2}

Hall's (2009) group-stalking incidents skewed towards Objective (physical) events $(n=73$ discrete events with ten themes) compared to Subjective (psychological) experiences ( $n$ 
$=48$ discrete events with eight themes). Thus, Hall's narrative appears to be composed primarily of tangible (60\%) versus private (40\%) information. Our next step was to scrutinise the meta-patterns in the 18 themes that manifested across the 121 discrete experiences. Yet a confound arises with qualitative data from commercial books or other modified sources. Particularly, the veracity or completeness of details are unknown with copyedited text, as opposed to witness interview transcripts or affidavits.

One solution is to consider only the obvious and important dominant themes in an account rather than include minor (or incidental) themes that could be unreliable for several reasons. Taking this approach first, we inspected Hall's dominant themes as defined by those SSE items with an above average ( $>7$ ) number of associated experiences (Column 4: Table 2). This vetting pinpointed eight dominant themes within Hall's (2009) account (cf. Table 3).

Table 3 compares meta-patterns in Hall's themes to those in Houran et al.'s (2019b) Rasch (1960/1980) models of haunt accounts. Our goal was to assess whether the phenomenology of Hall's (2009) dominant themes closely matched one of the five types of haunt narratives (i.e., spontaneous, primed, lifestyle, fantasy, or illicit). Specifically, it might be expected that Hall's (2009) themes with higher frequencies of experiences (Column 2) should correspond to haunt-type anomalies with lower logit-values (Column 3) (i.e., "easier" endorsement, or relatively more common experiences). Likewise, anomalies with higher logit-values for haunt experiences (i.e., "harder" endorsement, or relatively rarer experiences) should correlate to themes in Hall (2009) with comparatively lower frequencies. To reiterate, lower correlations in this exercise indicate greater levels of overall compatibility between the phenomenology of Hall's experiences and specific haunt narratives.

To clarify, a logit is the unit of measurement in Rasch scaling that indicates the point along an interval-level continuum where a given item (or theme) is positioned, and thus the likelihood of being endorsed, relative to other items (or themes) along the common dimension. Note that Houran et al. (2019b) found that logit-values for some items (experiences) shift in haunt accounts from different contexts, i.e., specific experiences were underor over-reported in narratives derived from "spontaneous, primed, lifestyle, fantasy, or illicit" conditions. Thus, these narrative-specific hierarchies potentially have diagnostic value.

Table 3 suggests that the dominant phenomenology of Hall's (2009) group-stalking experiences most closely approximates spontaneous ghostly episodes $(r=-.37)$, with the next closest parallel being fantasy haunt narratives $(r=.17)$. Nevertheless, this interpretation alters when Hall's (2009) collective phenomenology is considered, i.e., minor themes are also included in the calculations. In this scenario, the Pearson product moment coefficients $(r)$ between the frequencies of Hall's specific experiences and their respective logit values from Houran et al. (2019b) change as follows: spontaneous $=.12$, primed $=.36$, lifestyle $=.21$, fantasy $=-.15$, and illicit $=-.12$. The collective phenomenology seems most aligned to the "fantasy" condition, although it also has characteristics consistent with "illicit" narratives.

It is difficult to resolve these patterns and nuances decisively based on the available data. None of the five narrative structures clearly or consistently emerges as the preferred match, which might suggest that Hall's (2009) account is an amalgam of narrative types. For example, we could speculate that Hall experienced some anomalous and legitimately spontaneous events that subsequently encouraged the development of fantasy elements, 
Table 3. Dominant themes in Hall (2009) compared to phenomenologies of various haunt-related narratives from Houran et al. (2019b).

\begin{tabular}{|c|c|c|c|c|c|c|}
\hline $\begin{array}{l}\text { Hall's (2009) Haunt-Type } \\
\text { experiences }\end{array}$ & $N$ & $\begin{array}{c}\text { "Spontaneous" } \\
\text { narratives (logit) }\end{array}$ & $\begin{array}{l}\text { "Primed" } \\
\text { narratives } \\
\text { (logit) }\end{array}$ & $\begin{array}{l}\text { "Lifestyle" } \\
\text { narratives } \\
\text { (logit) }\end{array}$ & $\begin{array}{l}\text { "Fantasy" } \\
\text { narratives } \\
\text { (logit) }\end{array}$ & $\begin{array}{l}\text { "Illicit" } \\
\text { narratives } \\
\text { (logit) }\end{array}$ \\
\hline $\begin{array}{l}\text { I felt guided, controlled or } \\
\text { possessed by an outside } \\
\text { force. }\end{array}$ & 8 & .84 & .16 & -.21 & .22 & -.08 \\
\hline $\begin{array}{l}\text { I was mysteriously touched in a } \\
\text { threatening manner, such as } \\
\text { a cut, bite, scratch, shove, } \\
\text { burn or strong pressure on } \\
\text { my body. }\end{array}$ & 8 & .44 & -.29 & -.29 & -.08 & -1.56 \\
\hline $\begin{array}{l}\text { Electrical or mechanical } \\
\text { appliances or equipment } \\
\text { functioned improperly or not } \\
\text { at all, including flickering } \\
\text { lights, power surges or } \\
\text { batteries "going dead" in } \\
\text { electronic devices (e.g., } \\
\text { camera, phone, etc.). }\end{array}$ & 8 & -.62 & -.04 & -.46 & -.58 & -20 \\
\hline $\begin{array}{l}\text { I heard on an audio recorder } \\
\text { mysterious sounds that could } \\
\text { be recognized or identified, } \\
\text { such as ghostly voices or } \\
\text { music (with or without } \\
\text { singing). }\end{array}$ & 9 & .24 & -.60 & -1.79 & -1.07 & -1.52 \\
\hline $\begin{array}{l}\text { I felt odd sensations in my } \\
\text { body, such as dizziness, } \\
\text { tingling, electrical shock, or } \\
\text { nausea (sick in my stomach). }\end{array}$ & 10 & -.47 & -.16 & -.11 & .66 & 1.02 \\
\hline $\begin{array}{l}\text { I saw objects breaking (or } \\
\text { discovered them broken), } \\
\text { like shattered or cracked } \\
\text { glass, mirrors or housewares. }\end{array}$ & 15 & .51 & .63 & 1.08 & -.91 & -1.61 \\
\hline $\begin{array}{l}\text { I heard mysterious sounds that } \\
\text { could be recognized or } \\
\text { identified, such as ghostly } \\
\text { voices or music (with or } \\
\text { without singing). }\end{array}$ & 16 & -.62 & .15 & -.20 & -.50 & .26 \\
\hline $\begin{array}{l}\text { I saw with my naked eye an } \\
\text { "un-obvious" ghost or } \\
\text { apparition - a human form } \\
\text { that looked like a living } \\
\text { person. }\end{array}$ & 18 & -.47 & .41 & 1.04 & .87 & .09 \\
\hline$r$ & & -.37 & .69 & .67 & .17 & .37 \\
\hline
\end{tabular}

Note: Lower logit values = more common/ "easier" to endorse; higher logit values = less common/ "harder" to endorse

with some or all their accompanying details perhaps embellished (unwittingly or deliberately) later by him, a copyeditor, or other source. Taken altogether, we essentially confirmed Hypothesis 1. On the other hand, findings only partially supported the prediction that Hall's (2009) experiences would align to the meta-patterns of "spontaneous" ghostly episodes (Hypothesis 2).

\section{Discussion}

This was a preliminary and limited exploration of the hypothesis that group-stalking accounts involve the same, or similar, attentional or perceptual processes inherent to 
reports of haunts or poltergeist-like disturbances. By extension, this includes the assumption that group-stalking is another personification or interpretation of the "encounter experience" (cf. Evans, 2001; Houran, 2000; Hufford, 2001). Although our analysis cannot conclusively establish whether ghostly episodes and group-stalking are different expressions of a core experience or phenomenon, our results appear reasonably consistent with this premise. Our conclusion fundamentally equates Hall's (2009) "group-stalking" account to Doris Bither's "paranormal persecution" narrative.

Three added conceptual similarities bolster the hypothesis of a core HP-S phenomenon in the present context. Firstly, persecutory thoughts, feelings, and physical violations that define group-stalking accounts exist in many ghost narratives other than the Doris Bither case. For example, subtle or passive forms arguably include reports of "sensed presences," or an inexplicable sensation of being in the company of an invisible force that is akin to feeling "under surveillance." This anomaly bridges many encounter experiences (e.g., Houran, 2000; Hufford, 2001), and other times narratives also can refer to the sudden or mysterious onset of unsettling feelings (Harte, 2000; Houran, 2002).

More overt or threatening forms of "paranormal persecution" appear as nighttime "Old Hag attacks" which likely represent episodes of sleep paralysis (Hufford, 2001). According to Powell (1997), the term nightmare described this phenomenon before it acquired its modern, generalised meaning. Powell (1997) described it specifically as "a phenomenon during which a person senses the presence of a malevolent agent, is unable to move, is consciously aware of the surroundings, experiences a sense of fear or dread, and often feels a pressing or strangling sensation. In addition to these core elements, auditory and visual hallucinations and respiratory difficulty are common" (p. 588). Although much rarer, some haunt-poltergeist accounts have also referenced bodily effects during waking states that mimic aspects of the Doris Bither case. These materializations include anomalous bites, cuts, scratches, welts, and perceived possession by outside forces (e.g., Amorim, 1990; Mulacz, 1999).

Beyond the threatening nature of some $S / O$ anomalies on a tangible level, we imagine that themes of fear, dread, threat, or persecution in haunt or poltergeist narratives relate, in part, to proxemics and specifically the sense of intrusion into one's personal space that these anomalies might stimulate. By way of explanation, social scientists recognise four levels of psychological space, i.e., intimate, personal, social, and public. Personal space is the region surrounding individuals that they regard as their psychological territory and physical domain. Most people value their personal space and feel discomfort, anger, or anxiety when this space is encroached (Hall, 1966). Broadly speaking, we hypothesise that the more proximal $S / O$ anomalies are to one's personal space, the more intense or prevalent the corresponding perceptions of threat or persecution.

This assumes there is no prevailing context that otherwise normalises these anomalous experiences for individuals. Without this, we suspect that the proximity of anomalous events, combined with their inherent ambiguity (Lange \& Houran, 2001a) and aberrant salience to percipients (Irwin, 2014; Irwin, Schofield, \& Baker, 2014), collectively induce a type of functional paranoia. This cognitive-affective state might be characterised as experients striving to resolve a personal conundrum grounded in Trickster-Theory, "Who did what to whom and if so, why (if at all)?" (Brantley, 2009, p. 1). This speculation agrees with Banerjee and Bloom (2014) who found that religious and paranormal belief significantly predicts the propensity to perceive the world in terms of agency purpose, and design. 
Secondly, group-stalking accounts often reference "gaslighting" (Hall, 2009, 2014), which typically denotes the determined efforts of an influencer to cause an intended target to doubt his/her own experiences, or even sanity (Knight, 2006; Thomas, 2017). Sheridan and James (2015, Table 4, pp. 15-17) found related effects in the reported reactions of people close to the T.I.s they surveyed. For instance, T.I.s often endorsed statements such as "Others said they were overreacting/being paranoid (74.0\%)", "Family/ friends did not take me seriously" (60.2\%), and "The police did not take me seriously" (40.6\%). They also found that $51.2 \%$ of the group-stalking claimants "Thought they were going mad" (p. 12). Similarly, "paranormal witnesses" are often aware that their anomalous experiences are unconventional and therefore they sometimes rationalise them with orthodox beliefs when discussing them publicly or when faced with skepticism (Drinkwater, Dagnall, \& Bate, 2013; Ohashi, Wooffitt, Jackson, \& Nixon, 2013; Schmied-Knittel \& Schetsche, 2005; for a discussion see: Drinkwater, Laythe et al., 2019).

Thirdly, occurrences of so-called "street theater" among the frequent complaints of T.I.s. This refers supposedly to premeditated actions or skits that take place in public settings and which are designed to unnerve or harass victims by inflicting sustained levels of stress and anxiety. However, T.I.s claim that these exhibitions are crafted such that uninformed observers are likely to dismiss them as random examples of bad luck or a series of unfortunate events. These happenings can therefore be viewed either as blatant manifestations of Trickster Theory (e.g., Hynes \& Doty, 1993; Jung, 1956, 1969) or Murphy's Law (i.e., "anything that can go wrong will go wrong," see Spark, 2006).

This "street theater" echoes some incidents frequently reported during investigative probes of ghostly episodes. Particularly, researchers can feel exasperated during fieldwork studies when instrumentation malfunctions unexpectedly (Laythe \& Houran, 2019; cf. Kruth \& Joines, 2016), or anomalous events often remit once investigations ensue (Roll, 1977). Other times, experients or participants in fieldwork studies can publicly disrupt or even sabotage proceedings with marked emotional or mental states associated with the perception or report of $S / O$ anomalies (see e.g., Houran, Wiseman, \& Thalbourne, 2002; Terhune, Ventola, \& Houran, 2007).

Assuming the present findings and interpretations are valid, we must still be careful to distinguish between etiologies of anomalous experiences versus the attributions imposed on them (see e.g., David, 2010; Lange, Ross, Dagnall, Irwin, \& Houran, 2019). Some of the base $S / O$ events might be grounded in ontological realities (Houran, 1997; Houran \& Lange, 1996b), but the corresponding interpretation(s) can still be erroneous or delusional. Clinically speaking, we posit that HP-S reflects the tendency of some individuals to adopt implausible or esoteric explanations for recurring anomalous experiences due to improper or biased consideration of evidence (see e.g., Irwin, Dagnall, \& Drinkwater, 2012; Prike, Arnold, \& Williamson, 2018; Ross, Hartig, \& McKay, 2017; van Elk, 2015; for a counterpoint see: Laythe \& Owen, 2012).

This supposition aligns in important ways to the Threat Anticipation Cognitive Model (Ben-Zeev, Ellington, Swendsen, \& Granholm, 2011; Freeman, Garety, Kuipers, Fowler, \& Bebbington, 2002) that suggests persecutory ideations result from emotional processes, anomalous experiences, and reasoning biases. Advocates of this view specifically argue that a person's emotions give significant meaning to strange, ambiguous, or coincidental experiences, whereas reasoning biases induce paranoia or delusions of persecution. However, we do not imply that every ghostly episode or potential expression of HP-S is 
automatically a negative experience. In particular, S/O anomalies would seem to foster comfort, wonder, or awe when their interpretation is grounded in terms or beliefs that are non-threatening to one's personal space. These could include pleasant notions of angels or mystical forces (Houran \& Lange, 1997; Lange \& Houran, 1996), shamanic power animals (Houran, Lange, \& Crist-Houran, 1997), or deceased loved ones (Evrard, 2017).

More rigorous studies are now needed to determine whether our findings and conclusions generalise across group-stalking reports. Methodologies like Rasch scaling (e.g., Lange, 2017) or computerised Latent Semantic Analysis (e.g., Lange, Greyson, \& Houran, 2015) seem more powerful to evaluate big-data sets than rudimentary content analyses as used here and elsewhere (e.g., Drinkwater et al., 2013; Simmonds-Moore, 2016). Additionally, investigating the nuances and commonalities between ghostly episodes and group-stalking might provide further insights about whether (i) each are variants on recognized forms of "mass (contagious) psychogenic illness" — which Wessely (1987) proposed as two discernible syndromes, i.e., "mass anxiety hysteria" and "mass motor hysteria" (cf. Ali-Gombe, Guthrie, \& McDermott, 1996), or (ii) each reflects some potential hybrid of these two syndromes.

Other considerations are personality or social factors that promote attributions of group-stalking versus supernatural agency (Hill et al., 2018, 2019). Anecdotes from Sheridan and James (2015) might offer insights here. Although their survey documented negative effects on T.I.s, group-stalking accounts often also specified positive impacts. Illustratively, many narratives ( $50 \%)$ indicated that being targeted confirmed their beliefs along the lines of "I have always stood out" or "I have always been special/ different." Accordingly the psychology of T.I.s might be rooted in neuroticism, narcissism, superiority, or grandiosity, or a sense of disconnectedness or loneliness.

Moreover, research should also examine if the psychometric profiles of focus persons in ghostly episodes apply to self-described T.I.s. Many studies on paranormal belief and experience strongly suggest there is an "encounter-prone personality" grounded in a permeable (or thin) mental boundary structure (e.g., Houran, Kumar, et al., 2002; Parra, 2018). This profile might even capitalise on the potential biological basis or genetic predisposition for anomalous experience (McClenon, 2004, 2012; Winkelman, 2004, 2018).

All told, we think that the proposed syndrome model (i.e., HP-S) characterises the phenomenology of these anomalous episodes more accurately than blanket terminology like "(entity) encounter experiences." And, studies might well uncover other novel or surprising personifications of HP-S and thereby establish that the core phenomenon is more prevalent or malleable than current surveys even suggest. Research must now test the validity of this hypothesised construct, one which many readers might regard as controversial. We likewise sympathise with the reservations of researchers and practitioners over the invention of new terms, labels, or concepts that seemingly pathologize meager descriptions of certain attitudes and behaviours. Psychiatrist Peter Bregging eloquently summed up this concern with his observation that, "In reality, psychiatric diagnosing is a kind of spiritual profiling that can destroy lives and frequently does" (Breggin, 2010, para. 2). Consequently, we intend for the HP-S moniker to be behaviourally descriptive versus medically diagnostic.

Lastly, this study helps to corroborate the utility of the SSE measure for various qualiquantitative studies of ghostly episodes and kindred experiences. We hope that our approach motivates wider investigations of other "everyday" cases or phenomena in clinical or abnormal psychologies masquerading as parapsychological events or vice versa. In 
contrast to hypnosis (Noble \& McConkey, 1995), experiments using structured or simulated settings with non-clinical samples (French, Haque, Bunton-Stasyshyn, \& Davis, 2009; Laythe et al., 2017), quasi-experimental tasks with clinical patients (Caputo, 2014; Freeman et al., 2015), or neuroimaging (Blackwood et al., 2000; Kossowska, Szwed, Wronka, Czarnek, \& Wyczesany, 2016), the study of anomalous experiences as exemplified here offers an alternative, innocuous, and ecologically-valid way to research the formation or maintenance of delusional ideations (pathological or non-pathological) that are otherwise difficult to investigate from a behavioural science perspective due to their private nature.

\section{Notes}

1. We use "HP-S" vs "HPS," because the latter acronym is already prevalent in the clinical literature to reference many different disorders or medical topics

2. Early investigators surmised that "hysteria" was sometimes involved in haunt-related cases (see e.g., Grasset, 1903-1904), so Lange and Houran's basic hypothesis is not wholly new or original.

3. "Carol Carmel, Armed Recovery Agent," Updated Aug 22, 2017. Retrieved October 31, 2018 from. https://www.quora.com/How-do-you-know-if-youre-being-gang-stalked. Note: emphasis added to denote symptoms of stalking that seemingly map against those for haunt-poltergeist accounts. This account has a raw tally of nine types of anomalous "ghostly" events that equates to a Rasch score of 48.6 ( $S E=2.8$ ) on the SSE measure, which has a $M=50$.

\section{Disclosure statement}

No potential conflict of interest was reported by the authors.

\section{ORCID}

Ciaran O'Keeffe (D) http://orcid.org/0000-0002-9655-3261

James Houran (iD http://orcid.org/0000-0003-1725-582X

Neil Dagnall (D) http://orcid.org/0000-0003-0657-7604

Kenneth Drinkwater (D) http://orcid.org/0000-0002-4015-0578

Lorraine Sheridan (D) http://orcid.org/0000-0002-8705-0531

\section{References}

Ali-Gombe, A., Guthrie, E., \& McDermott, N. (1996). Mass hysteria: One syndrome or two? British Journal of Psychiatry, 168, 633-635. doi:10.1192/bjp.168.5.633

Amorim, M-A. (1990). The Guarulhos poltergeist: A reassessment of Andrade's (1984) monograph. Journal of the Society for Psychical Research, 56, 193-207.

Bader, C. D. (2017). Paranormal America: Ghost encounters, UFO sightings, bigfoot hunts, and other curiosities in religion and culture (2nd ed). New York, NY: York University Press. doi:10.2307/j. ctt1gk08qb.

Balaratnasingama, S., \& Janca, A. (2006). Mass hysteria revisited. Current Opinion in Psychiatry, 19, 171-174. doi:10.1097/01.yco.0000214343.59872.7a

Banerjee, K., \& Bloom, P. (2014). Why did this happen to me? Religious believers' and non-believers' teleological reasoning about life events. Cognition, 133, 277-303. doi:10.1016/j.cognition.2014.06. 017 
Ben-Zeev, D., Ellington, K., Swendsen, J., \& Granholm, E. (2011). Examining a cognitive model of persecutory ideation in the daily life of people with schizophrenia: A computerized experience sampling study. Schizophrenia Bulletin, 37, 1248-1256. doi:10.1093/schbul/sbq041

Blackwood, N. J., Howard, R. J., Ffytche, D. H., Simmons, A., Bentall, R. P., \& Murray, R. M. (2000). Imaging attentional and attributional bias: An fMRI approach to the paranoid delusion. Psychological Medicine, 30, 873-883. doi:10.1017/S0033291799002421

Booker, M. K. (2009). Red, white and spooked: The supernatural in American culture. Westport, CT: Praeger.

Boss, L. P. (1997). Epidemic hysteria: A review of the published literature. Epidemiological Reviews, 19, 233-243. doi:10.1093/oxfordjournals.epirev.a017955

Brantley, J. (2009). Who did what to whom and if so, why (if at all)? Trickster's Way, 5(2), 1-3. Retrieved from http://digitalcommons.trinity.edu/trickstersway/vol5/iss2/2

Breggin, P. R. (2010). The hazards of psychiatric diagnosis. Huffington Post: Life blog, retrieved from: https://www.huffpost.com/entry/mental-health-the-hazards_b_618507 Also available at: https:// breggin.com/the-hazards-of-psychiatric-diagnosis/

British Medical Association. (2018). BMA illustrated medical dictionary (4th ed). London, England: DK Publishing.

Burrough, B., Ellison, E., \& Andrews, S. (2014). The Snowden saga: A shadowland of secrets and light. Vanity Fair: Special Report. Retrieved from https://www.vanityfair.com/news/politics/2014/05/ edward-snowden-politics-interview

Caputo, G. B. (2014). Archetypal-imaging and mirror-gazing. Behavioral Sciences, 4, 1-13. doi:10.3390/ bs4010001

Carrington, H., \& Fodor, N. (1951). Haunted people: Story of the poltergeist down the centuries. New York, NY: E. P. Dutton \& Co.

Catanzaro, M. (1988). Using qualitative analytical techniques. In P. Woods \& M. Catanzaro (Eds.), Nursing research; theory and practice (pp. 437-456). New York, NY: C.V. Mosby Co.

Chen, C. S., Yen, C. F., Lin, H. F., \& Yang, P. (2003). Mass hysteria and perceptions of the supernatural among adolescent girl students in Taiwan. Journal of Nervous and Mental Disease, 191, 122-123. doi:10.1097/01.NMD.0000050941.22170.A5

Colligan, M. J., Pennebaker, J. W., \& Murphy, L. R. (1982). Mass psychogenic illness: A social and psychological analysis. Hillsdale, NJ: Erlbaum.

Dagnall, N., Drinkwater, K., Denovan, A., \& Parker, A. (2015). Suggestion, belief in the paranormal, proneness to reality testing deficits and perception of an allegedly haunted building. Journal of Parapsychology, 79, 87-104.

David, A. S. (2010). Why we need more debate on whether psychotic symptoms lie on a continuum with normality. Psychological Medicine, 40, 1935-1942. doi:10.1017/S0033291710000188

De Felitta, F. (1978). The entity. New York, NY: G. P. Putnam's sons.

Dein, S. (2012). Mental health and the paranormal. International Journal of Transpersonal Studies, 31 , 61-74. doi:10.24972/ijts.2012.31.1.61

Drinkwater, K., Dagnall, N., \& Bate, L. (2013). Into the unknown: Using interpretative phenomenological analysis to explore personal accounts of personal paranormal experiences. Journal of Parapsychology, 77, 281-294.

Drinkwater, K., Dagnall, N., Denovan, A., \& Parker, A. (2019). The moderating effect of mental toughness: Perception of risk and belief in the paranormal. Psychological Reports, 122, 268-287. doi:10. $1177 / 0033294118756600$

Drinkwater, K., Laythe, B., Houran, J., Dagnall, N., O'Keeffe, C., \& Hill, S. A. (2019). Understanding gaslighting effects via the VAPUS model for ghost narratives. Australian Journal of Parapsychology, 19, 143-179.

Evans, H. (1987). Gods, spirits, cosmic guardians: A comparative study of the encounter experience. Wellingborough: Aquarian.

Evans, H. (2001). The ghost experience in a wider context. In J. Houran \& R. Lange (Eds.), Hauntings and poltergeists: Multidisciplinary perspectives (pp. 41-61). Jefferson, NC: McFarland \& Co.

Evans, J., Lange, R., Houran, J., \& Lynn, S. J. (2018). Further psychometric exploration of the transliminality construct. Psychology of Consciousness: Theory, Research, and Practice, Advance online publication. doi:10.1037/cns0000163 
Evrard, R. (2017). Ghost in the machine: A clinical view of anomalous telecommunication experiences. Journal of Exceptional Experiences and Psychology, 5, 21-30.

Freeman, D., Emsley, R., Dunn, G., Fowler, D., Bebbington, P., Kuipers, E., ... Garety, P. (2015). The stress of the street for patients with persecutory delusions: A test of the symptomatic and psychological effects of going outside into a busy urban area. Schizophrenia Bulletin, 41, 971-979. doi:10. 1093/schbul/sbu173

Freeman, D., Garety, P. A., Kuipers, E., Fowler, D., \& Bebbington, P. E. (2002). A cognitive model of persecutory delusions. British Journal of Clinical Psychology, 41, 331-347. doi:10.1348/ 014466502760387461

French, C. C., Haque, U., Bunton-Stasyshyn, R., \& Davis, R. (2009). The 'haunt' project: An attempt to build a 'haunted' room by manipulating complex electromagnetic fields and infrasound. Cortex, 45, 619-629. doi:10.1016/j.cortex.2007.10.011

Goldstein, D. E., Grider, S. A., \& Thomas, J. B. (2007). Haunting experiences: Ghosts in contemporary folklore. Logan, UT: Utah State University Press. doi:10.2307/j.ctt4cgmqg.

Grasset, J. (1903-1904). The history of a haunted house. Proceedings of the Society for Psychical Research, 18, 464-480.

Hall, E. T. (1966). The hidden dimension. New York, NY: Anchor Books.

Hall, J. (2009). A new breed: Satellite terrorism in America. New York, NY: Strategic Book Publishing.

Hall, J. (2011). Guinea pigs: Technologies of control (1st ed). Houston, TX: Strategic Book Publishing and Rights Co.

Hall, J. (2014). Guinea pigs: Technologies of control (2nd ed). Houston, TX: Strategic Book Publishing and Rights Co.

Harte, T. M. (2000). Contextual mediation of perceptions during hauntings and poltergeist-like experiences: A replication and extension. Perceptual and Motor Skills, 91, 451-459. doi:10.2466/ pms.2000.91.2.451

Hastings, A. (1983). A counseling approach to parapsychological experience. Journal of Transpersonal Psychology, 15, 143-167.

Hill, S. A. (2017). Scientifical Americans: The culture of amateur paranormal researchers. Jefferson, NC: McFarland \& Co. doi:10.1038/scientificamerican1217-12 doi:10.1038/scientificamerican1217-48 doi:10.1038/scientificamerican0817-22 doi:10.1038/scientificamerican1117-20.

Hill, S. A., Laythe, B., Dagnall, N., Drinkwater, K., O'Keeffe, C., Ventola, A., \& Houran, J. (2019). "Memespirited": II. Illustrations of the VAPUS model for ghost narratives. Australian Journal of Parapsychology, 19, 5-43.

Hill, S. A., O'Keeffe, C., Laythe, B., Dagnall, N., Drinkwater, K., Ventola, A., \& Houran, J. (2018). "Memespirited": I. The VAPUS model for understanding the prevalence and potency of ghost narratives. Australian Journal of Parapsychology, 18, 117-152.

Houran, J. (1997). Ambiguous origins and indications of "poltergeists.". Perceptual and Motor Skills, 84, 339-344. doi:10.2466/pms.1997.84.1.339

Houran, J. (2000). Toward a psychology of 'entity encounter experiences'. Journal of the Society for Psychical Research, 64, 141-158.

Houran, J. (2002). Analysis of haunt experiences at a historical Illinois landmark. Australian Journal of Parapsychology, 2, 97-124.

Houran, J., Kumar, V. K., Thalbourne, M. A., \& Lavertue, N. E. (2002). Haunted by somatic tendencies: Spirit infestation as psychogenic illness. Mental Health, Religion \& Culture, 5, 119-133. doi:10.1080/ 13674670210141061

Houran, J., \& Lange, R. (1996a). Diary of events in a thoroughly unhaunted house. Perceptual and Motor Skills, 83, 499-502. doi:10.2466/pms.1996.83.2.499

Houran, J., \& Lange, R. (1996b). Hauntings and poltergeist-like episodes as a confluence of conventional phenomena: A general hypothesis. Perceptual and Motor Skills, 83, 1307-1316. doi:10.2466/ pms.1996.83.3f.1307

Houran, J., \& Lange, R. (1997). Hallucinations that comfort: Contextual mediation of deathbed visions. Perceptual and Motor Skills, 84, 1491-1504. doi:10.2466/pms.1997.84.3c.1491

Houran, J., \& Lange, R. (eds.). (2001). Hauntings and poltergeists: Multidisciplinary perspectives. Jefferson, NC: McFarland \& Co. 
Houran, J., Lange, R., \& Crist-Houran, M. (1997). An assessment of contextual mediation in trance states of shamanic journeys. Perceptual and Motor Skills, 85, 59-65. doi:10.2466/pms.1997.85.1.59

Houran, J., Laythe, B., O'Keeffe, C., Dagnall, N., Drinkwater, K., \& Lange, R. (2019a). Quantifying the phenomenology of ghostly episodes: Part I - need for a standard operationalization. Journal of Parapsychology, 83, 25-46. doi:10.30891/jopar.2019.01.03

Houran, J., Lange, R., Laythe, B., Dagnall, N., Drinkwater, K., \& O'Keeffe, C. (2019b). Quantifying the phenomenology of ghostly episodes - Part II: A rasch model of spontaneous accounts. Journal of Parapsychology, 83, 170-194.

Houran, J., Wiseman, R., \& Thalbourne, M. A. (2002). Perceptual-personality characteristics associated with naturalistic haunt experiences. European Journal of Parapsychology, 17, 17-44.

Hufford, D. J. (1982). The terror that comes in the night: An experience-centered study of supernatural assault traditions. Philadelphia, PA: University of Pennsylvania Press.

Hufford, D. J. (2001). An experience-centered approach to hauntings. In J. Houran \& R. Lange (Eds.), Hauntings and poltergeists: Multidisciplinary perspectives (pp. 18-40). Jefferson, NC: McFarland \& Co.

Hynes, W. J., \& Doty, W. G. (eds.). (1993). Mythical trickster figures: Contours, contexts, and criticisms. Tuscaloosa, AL: University of Alabama Press.

Irwin, H. J. (2014). Aberrant salience and motivation as factors in the formation of belief in scientifically unaccepted phenomena. Journal of Scientific Exploration, 28, 633-645.

Irwin, H. J., Dagnall, N., \& Drinkwater, K. (2012). Paranormal beliefs and cognitive processes underlying the formation of delusions. Australian Journal of Parapsychology, 12, 107-126.

Irwin, H. J., Schofield, M. B., \& Baker, I. S. (2014). Dissociative tendencies, sensory-processing sensitivity, and aberrant salience as predictors of anomalous experiences and paranormal attributions. Journal of the Society for Psychical Research, 78, 193-206.

Jawer, M. (2006). Environmental sensitivity: Inquiry into a possible link with apparitional experience. Journal of the Society for Psychical Research, 70, 25-47.

Jung, C. G. (1956). On the psychology of the trickster figure. In P. Radin (Ed.), ), The trickster: A study in American Indian mythology (R.F.C. Hull, Trans.) (pp. 195-211). New York, NY: Schocken Books.

Jung, C. G. (1969). Four archetypes: Mother/ rebirth/ spirit/ trickster. Princeton, NJ: Princeton University Press.

Knight, Z. G. (2006). Some thoughts on the psychological roots of the behavior of serial killers as narcissists: An object relations perspective. Social Behavior and Personality: An International Journal, 34, 1189-1206. doi:10.2224/sbp.2006.34.10.1189

Kossowska, M., Szwed, P., Wronka, E., Czarnek, G., \& Wyczesany, M. (2016). Anxiolytic function of fundamentalist beliefs: Neurocognitive evidence. Personality and Individual Differences, 101, 390-395. doi:10.1016/j.paid.2016.06.039

Kruth, J. G., \& Joines, W. T. (2016). Taming the ghost within: An approach toward addressing apparent electronic poltergeist activity. Journal of Parapsychology, 80, 70-86.

Lange, R. (2017). Rasch scaling and cumulative theory-building in consciousness research. Psychology of Consciousness: Theory, Research and Practice, 4, 135-160. doi:10.1037/cns0000118

Lange, R., Greyson, B., \& Houran, J. (2015). Using computational linguistics to understand near-death experiences: Concurrent validity for the NDE Scale. Psychology of Consciousness: Theory, Research, and Practice, 2, 79-89. doi:10.1037/cns0000040

Lange, R., \& Houran, J. (1996). Role of contextual mediation in direct versus reconstructed angelic encounters. Perceptual and Motor Skills, 83, 1259-1270. doi:10.2466/pms.1996.83.3f.1259

Lange, R., \& Houran, J. (2001a). Ambiguous stimuli brought to life: The psychological dynamics of hauntings and poltergeists. In J. Houran \& R. Lange (Eds.), Hauntings and poltergeists: Multidisciplinary perspectives (pp. 280-306). Jefferson, NC: McFarland \& Co.

Lange, R., \& Houran, J. (2001b). Power laws and autoregressive catastrophes: The dynamic properties of poltergeist episodes. Technical report to the Institut für Grenzgebiete der Psychologie und Psychohygiene (IGPP), Freiburg i. Br., Germany.

Lange, R., Ross, R. M., Dagnall, N., Irwin, H. J., \& Houran, J. (2019). Anomalous experiences and paranormal attributions: Psychometric challenges in studying their measurement and relationship. Psychology of Consciousness: Theory, Research, and Practice, Advance online publication: doi:10. 1037/cns0000187 
Laythe, B., \& Houran, J. (2019). Concomitant object movements and EMF-spikes at a purported haunt. Journal of the Society for Psychical Research, 83, 214-232.

Laythe, B., Houran, J., \& Ventola, A. (2018). A split-sample psychometric study of 'haunters.' Journal of the Society for Psychical Research, 81, 193-218.

Laythe, B. R., Laythe, E. C., \& Woodward, L. (2017). A test of an occult themed séance: Examining anomalous events, psychosomatic symptoms, transliminality, and electromagnetic fields. Journal of Scientific Exploration, 31, 572-624.

Laythe, B. R., \& Owen, K. (2012). Paranormal belief and the strange case of haunt experiences: Evidence of a neglected population. Journal of Parapsychology, 76, 79-108.

Maher, M. C. (2015). Ghosts and poltergeists: An eternal enigma. In E. Cardeña, J. Palmer, \& D. Marcussion-Clavertz (Eds.), Parapsychology: A handbook for the 21st century (pp. 327-240). Jefferson, NC: McFarland \& Co.

Mash, E. J. (1989). Treatment of child and family disturbance: A behavioral systems perspective. In E. J. Mash, \& R. A. Barkley (Eds.), Treatment of childhood disorders (pp. 3-38). New York, NY: Guilford.

Mathijsen, F. P. (2016). Anomalous experiences and schizotypy: Which comes first? The Hermit Crab syndrome hypothesis. Mental Health, Religion \& Culture, 19, 113-123. doi:10.1080/13674676.2015. 1004627

McClenon, J. (2004). How shamanism began: Human evolution, dissociation, and anomalous experience. In J. Houran (Ed.), From shaman to scientist: Essays on humanity's search for spirits (pp. 21-58). Lanham, MD: Scarecrow Press.

McClenon, J. (2012). A community survey of psychological symptoms: Evaluating evolutionary theories regarding shamanism and schizophrenia. Mental Health, Religion \& Culture, 15, 799-816. doi:10.1080/13674676.2011.637913

McPhate, M. (2016). United States of paranoia: They see gangs of stalkers. New York Times, Health section online article. Retrieved from: https://www.nytimes.com/2016/06/11/health/gangstalking-targeted-individuals.html

Montanelli, D. E. G., \& Parra, A. (2002-2005). Are spontaneous anomalous/paranormal experiences disturbing?: A survey among under-graduate students. International Journal of Parapsychology, $13,1-14$.

Mulacz, P. (1999). Eleonore Zugun: The re-evaluation of a historic RSPK case. Journal of Parapsychology, 63, 15-45.

Musgrave, J. B., \& Houran, J. (2000). Flight and abduction in witchcraft and UFO lore. Psychological Reports, 86, 669-688. doi:10.2466/pr0.2000.86.2.669

Nisbet, B. C. (1979). A West Croyden "poltergeist:" Report and comments. Journal of the Society for Psychical Research, 50, 229-237.

Noble, J., \& McConkey, K. M. (1995). Hypnotic sex change: Creating and challenging a delusion in the laboratory. Journal of Abnormal Psychology, 104, 69-74. doi:10.1037/0021-843X.104.1.69

Ohashi, Y., Wooffitt, R., Jackson, C., \& Nixon, Y. (2013). Discourse, culture and extraordinary experiences: Observations from a comparative, qualitative analysis of Japanese and UK English accounts of paranormal phenomena. Western Journal of Communication, 77, 466-488. doi:10.1080/ 10570314.2012.714047

O'Keeffe, C., \& Parsons, S. (2010). Haunting experiences: An integrative approach. In M. Smith (Ed.), Anomalous experiences: Essays from parapsychological and psychological perspectives (pp. 108119). Jefferson, NC: McFarland \& Co.

O'Mahony, M. (1978). Smell illusions and suggestions: Reports of smells contingent on tones played on television and radio. Chemical Senses and Flavour, 3, 183-189. doi:10.1093/chemse/3.2.183

Ortega, X. (2009). The entity - Interview with Doris Bother's son. Ghost Theory blog. Retrieved from http://www.ghosttheory.com/2009/05/18/the-entity-interview-with-doris-bithers-son.

Parra, A. (2018). Perceptual-personality variables associated with entity encounter experiences. Australian Journal of Parapsychology, 18, 23-48.

Paullet, K. L., Rota, D. R., \& Swan, T. T. (2009). Cyberstalking: An exploratory study of students at a midAtlantic university. Issues in Information Systems, X, 640-649.

Powell, L. C. (1997). Night hag. In T. A. Green (Ed.), Folklore: An encyclopedia of beliefs, customs, tales, music, and art (Vol. 1, pp. 588-590). Santa Barbara, CA: ABC-CLIO. 
Prike, T., Arnold, M. M., \& Williamson, P. (2018). The relationship between anomalistic belief and biases of evidence integration and jumping to conclusions. Acta Psychologica, 190, 217-227. doi:10.1016/j.actpsy.2018.08.006

Rabeyron, T., \& Loose, T. (2015). Anomalous experiences, trauma, and symbolization processes at the frontiers between psychoanalysis and cognitive neurosciences. Frontiers in Psychology, 6, 1926. doi:10.3389/fpsyg.2015.01926

Radford, B., \& Bartholomew, R. (2001). Pokémon contagion: Photosensitive epilepsy, or mass psychogenic illness? Southern Medical Journal, 94, 197-204. doi:10.1097/00007611-200194020-00005

Rasch, G. (1960). Probabilistic models for some intelligence and attainment tests (1st ed). Copenhagen, Denmark: Danish Institute for Educational Research.

Rasch, G. (1980). Probabilistic models for some intelligence and attainment tests (2nd ed). Chicago, IL: University of Chicago Press.

Rogo, D. S. (1982). The poltergeist and family dynamics. Journal of the Society for Psychical Research, 51, 233-237.

Roll, W. G. (1977). Poltergeists. In B. B. Wolman (Ed.), Handbook of parapsychology (pp. 382-413). New York, NY: Van Nostrand Reinhold.

Ross, R. M., Hartig, B., \& McKay, R. (2017). Analytic cognitive style predicts paranormal explanations of anomalous experiences but not the experiences themselves: Implications for cognitive theories of delusions. Journal of Behavior Therapy and Experimental Psychiatry, 56, 90-96. doi:10.1016/j.jbtep. 2016.08.018

Sar, V., Alioğlu, F., \& Akyüz, G. (2014). Experiences of possession and paranormal phenomena among women in the general population: Are they related to traumatic stress and dissociation? Journal of Trauma \& Dissociation, 15, 303-318. doi:10.1080/15299732.2013.849321

Schmied-Knittel, I., \& Schetsche, M. (2005). Everyday miracles: Results of a representative survey in Germany. European Journal of Parapsychology, 20, 3-21.

Sharps, M. J., Newborg, E., Van Arsdall, S., DeRuiter, J., Hayward, B., \& Alcantar, B. (2010). Paranormal encounters as eyewitness phenomena: Psychological determinants of atypical perceptual interpretations. Current Psychology, 29, 320-327. doi:10.1007/s12144-010-9091-9

Sheridan, L. P., \& James, D. V. (2015). Complaints of group-stalking ('gang-stalking'): An exploratory study of their nature and impact on complainants. Journal of Forensic Psychiatry \& Psychology, 26, 601-623. doi:10.1080/14789949.2015.1054857

Simmonds-Moore, C. A. (ed.). (2012). Exceptional experience and health. Jefferson, NC: McFarland \& Co. Simmonds-Moore, C. A. (2016). An interpretative phenomenological analysis exploring synesthesia as an exceptional experience: Insights for consciousness and cognition. Qualitative Research in Psychology, 13, 303-327. doi:10.1080/14780887.2016.1205693

Spark, N. T. (2006). A history of Murphy's law. Los Angeles, CA: Periscope Film.

Taff, B. E. (2014). Aliens above, ghosts below. Harpers Ferry, WV: Cosmic Pantheon Press.

Terhune, D. B., Ventola, A., \& Houran, J. (2007). An analysis of contextual variables and the incidence of photographic anomalies at an alleged haunt and a control site. Journal of Scientific Exploration, $21,99-120$.

Thomas, N. K. (2017). Gaslighting, betrayal and the boogeyman: Personal reflections on the American Psychological Association, PENS and the involvement of psychologists in torture. International Journal of Applied Psychoanalytic Studies, 14, 125-132. doi:10.1002/aps.1520

van Elk, M. (2015). Perceptual biases in relation to paranormal and conspiracy beliefs. PLoS ONE, 10(6), e0130422. doi:10.1371/journal.pone.0130422

Ventola, A., Houran, J., Laythe, B., Storm, L., Parra, A., Dixon, J., \& Kruth, J. G. (2019). A transliminal 'disease' model of poltergeist 'agents.' Journal of the Society for Psychical Research, 83, 25-46. doi:10. 30891/jopar.2019.01.03

Wessely, S. (1987). Mass hysteria: Two syndromes? Psychological Medicine, 17, 109-120. doi:10.1017/ S0033291700013027

Wessely, S. (2000). Responding to mass psychogenic illness. New England Journal of Medicine, 342, 129-130. doi:10.1056/NEJM200001133420212 
Winkelman, M. J. (2004). Spirits as human nature and the fundamental structures of consciousness. In J. Houran (Ed.), From shaman to scientist: Essays on humanity's search for spirits (pp. 59-96). Lanham, MD: Scarecrow.

Winkelman, M. J. (2018). An ontology of psychedelic entity experiences in evolutionary psychology and neurophenomenology. Journal of Psychedelic Studies, 2, 5-23. doi:10.1556/2054.2018.002

Zuboff, S. (2019). The age of surveillance capitalism: The fight for a human future at the new frontier of power. New York, NY: Public Affairs. 